\title{
AGROMETEOROLOGIA
}

\section{BALANÇO DE ENERGIA NA CULTURA DE PEPINEIRO EM AMBIENTE NATURAL E PROTEGIDO ${ }^{(1)}$}

\author{
EMERSON GALVANI $^{(2,3)} ;$ JOÃO FRANCISCO ESCOBEDO ${ }^{(2)}$
}

\begin{abstract}
RESUMO
Avaliaram-se, diariamente, neste trabalho, o saldo de radiação (SR), o fluxo de calor no solo (G), o fluxo de calor latente de evaporação (LE) e o fluxo de calor sensível $(\mathrm{H})$ ao longo do ciclo da cultura de pepineiro cultivado dentro e fora de casa de vegetação em ciclo de outono-inverno e primaveraverão. O SR e o $\mathrm{G}$ foram quantificados e o LE e o H estimados em dois níveis distintos pelo método da razão de Bowen. Os resultados mostram que a maior parte da energia disponível foi utilizada no fluxo de calor latente de evaporação e que os componentes do balanço de energia apresentaram-se mais consistentes em níveis próximos ao dossel da cultura e em ambiente protegido.

Palavras-chave: balanço de energia, cultivo protegido, pepineiro, evapotranspiração.

\section{ABSTRACT \\ ENERGY BALANCE IN CUCUMBER CROP IN GREENHOUSE AND FIELD CONDITIONS}

The net radiation balance (SR), the flow of heat in the soil (G), the flow of latent heat of evaporation (LE) and the flow of sensitive heat $(\mathrm{H})$ were evaluated daily along the cycle of the cucumber crop cultivated inside and outside greenhouse in the autumn-winter and spring-summer cycles. SR and G were quantified and LE and $\mathrm{H}$ were estimated at two different levels by the method of Bowen ratio. The results showed that most of the available energy was used in the flow of latent heat of evaporation and that the components of the energy balance were more consistent in levels close to the dossel of the crop and in the greenhouse.
\end{abstract}

Key words: energy balance, greenhouse, cucumber, evapotranspiration.

\section{INTRODUÇÃO}

O conhecimento da evapotranspiração, ou fluxo de calor latente de evapotranspiração (LE), contribui para o planejamento racional da técnica de irrigação e fornece, juntamente com outros elementos meteorológicos, subsídios básicos à regionalização das áreas mais adequadas ao desenvolvimento de determinadas espécies vegetais. Além disso, a avaliação da quantidade de água exigida por determinada cultura torna-se ainda mais importante, sobretudo em regiões áridas ou com secas regulares, onde o crescimento e o desenvolvimento das plantas e, conseqüentemente, a produtividade são limitados pelo fator hídrico.
O método do balanço de energia (M.B.E.) possibilita determinar os valores da demanda atmosférica em escala horária e até mesmo em escalas menores. Apesar da grande diversidade de métodos para determinações em escala horária, somente as medidas lisimétricas e o método do balanço de energia fornecem resultados com eficácia. Considerando que a construção de um lisímetro de precisão é difícil e onerosa, e que seu campo de atuação se restringe ao local de instalação, o M.B.E., pela sua versatilidade e precisão oferecida, é ideal para tal finalidade.

Inúmera é a literatura que trata da partição do balanço de energia sobre as mais diversas culturas;

(1) Parte da tese de doutorado do primeiro autor, em Energia na Agricultura, apresentada à Faculdade de Ciências Agronômicas, Universidade Estadual Paulista (FCA/UNESP), Botucatu (SP). Recebido para publicação em 27 de dezembro de 2000 e aceito em 5 de junho de 2001.

$\left(^{2}\right)$ Departamento de Recursos Naturais (FCA/UNESP), Câmpus Lageado, Caixa Postal 237, 18603-970 Botucatu (SP). E-mail: galvani@fca.unesp.br

$\left({ }^{3}\right)$ Bolsista da FAPESP. 
faz-se desnecessário, aqui, descrevê-la extensivamente, propõe-se, apenas, a citação em ordem cronológica de alguns autores que a compõem: VILLA Nova, 1973; Villa Nova et al., 1975; Pedro Junior e Villa Nova, 1981; Nishimura et al., 1985; AlFONSI et al., 1986; Prates et al., 1987; Bergamaschi et al., 1988; Azevedo et al., 1989; Fontana et al., 1991; Oliver e SENE, 1992; YANG, 1995; CUNHA et al., 1996; JAEGER e KESSLER, 1997; Galvani et al., 1997 e Frisina, 1998. Contudo, observa-se número muito limitado de trabalhos que tratam da partição do balanço de energia ao longo de todo o ciclo de uma cultura e em ambientes protegidos, como estufas plásticas, por exemplo.

Diante disso, o presente trabalho tem por objetivo quantificar o saldo de radiação e os fluxos de calor no solo, estimar os fluxos de calor latente de evapotranspiração e de calor sensível pelo método da razão de Bowen, assim como sua partição ao longo de todo o ciclo da cultura de pepineiro, cultivado dentro e fora de estufa plástica em ciclos de outono-inverno e primavera-verão em dois níveis acima do dossel da cultura.

\section{MATERIAL E MÉTODOS}

\subsection{Campo experimental e manejo da cultura}

Desenvolveu-se o trabalho em área experimental do Departamento de Recursos Naturais da Faculdade de Ciências Agronômicas, UNESP, Câmpus de Botucatu (latitude: $22^{\circ} 51^{\prime} \mathrm{S}$; longitude: $48^{\circ} 26^{\prime} \mathrm{W}$ e altitude: $786 \mathrm{~m})$. A área constituiu-se de duas parcelas: uma interna, com ambiente protegido por cobertura de polietileno de $120 \mu \mathrm{m}$ de espessura com laterais de "sombrite" (malha de 50\%); outra externa, ambas com dimensões de 7 x $40 \mathrm{~m}$ e cultivadas com pepineiro, variedade Hokuhoo, tipo salada e de crescimento indeterminado, nos períodos de outono-inverno $(13 / 5 / 98$ a 10/9/98) e primavera-verão (10/11/98 a 10/2/99). Nos canteiros, o espaçamento entre plantas na linha foi de $0,3 \mathrm{~m}$ e de $0,7 \mathrm{~m}$ entre linhas.

Efetuou-se o controle de irrigação, com base nos valores de evapotranspiração obtidos em lisímetros de lençol freático constante instalados dentro e fora das casas de vegetação. Seis lisímetros (três unidades no interior e três em condição externa), dispostos entre as parcelas de cultivo, forneceram, mediante a diferença entre duas leituras consecutivas, os valores de evapotranspiração da cultura, os quais foram repostos no dia seguinte pelo sistema de gotejamento. Desenvolveu-se um modelo de regressão linear entre vazão e tempo para os gotejadores.

Para o cultivo de outono-inverno, em ambiente protegido e em condição de campo, verificados os resultados da análise química do solo, procedeu-se à correção à base de $2.250 \mathrm{~kg}$.ha ${ }^{-1}$ de calcário dolomítico (PNRT 100) e adubação com $115 \mathrm{~g} \cdot \mathrm{m}^{-2}$ de termofosfato com boro e zinco, $45 \mathrm{~g} \cdot \mathrm{m}^{-2}$ de superfosfato triplo e 30 g. $\mathrm{m}^{-2}$ de cloreto de potássio. Adicionou-se, também, matéria orgânica à base de esterco bovino à proporção de aproximadamente $6 \mathrm{~kg} \cdot \mathrm{m}^{-2}$ de canteiro. Todo esse material foi incorporado ao solo três semanas antes do início do transplante. Até a colheita dos primeiros frutos, efetuou-se a cobertura com 5,0 a 7,5 g de nitrato de cálcio e 1 a $2 \mathrm{~g}$ de nitrato de potássio por planta; após a colheita dos primeiros frutos, com 10 a $15 \mathrm{~g}$ de nitrato de cálcio e 2 a $5 \mathrm{~g}$ de nitrato de potássio. A maior dose foi aplicada quando o crescimento apresentava-se pequeno (internódio curto, folhas verde-amareladas), já a menor, quando a planta apresentava crescimento excessivo (folhas verde-escuras).

No período de primavera-verão, em ambiente protegido, utilizaram-se $3 \mathrm{~kg} . \mathrm{m}^{-2}$ de esterco de curral curtido para o preparo dos canteiros. Para adubação de plantio, fez-se uso de 60 g.m $\mathrm{m}^{-2}$ de termofosfato magnesiano, 10 g. $\mathrm{m}^{-2}$ de cloreto de potássio, $10 \mathrm{~g} \cdot \mathrm{m}^{-2}$ de sulfato de amônia e 10 g.m ${ }^{-2}$ de FTE BR9. Após dez dias do transplante, aplicaram-se $2,0 \mathrm{~g}$ de nitrato de potássio e 6,0 g de nitrato de cálcio por planta, semanalmente. Em ambiente externo, aplicou-se 1,3 t.ha ${ }^{-1}$ de calcário, além da adubação recomendada para o ambiente protegido. No início da maturação dos frutos, aumentou-se a dose de aplicação de nitrato de potássio para $4,0 \mathrm{~g}$ por planta por semana.

Efetuou-se o controle fitossanitário quando detectada a ocorrência de pragas ou doenças pelo diagnóstico foliar, conforme quadro 1.

\subsection{Instrumental utilizado}

Monitorou-se a temperatura do ar, utilizando-se de termopares de cobre-constantan e, como referência, sensor resistivo da Campbell. No total, instalaram-se doze termopares, metade em condições internas, metade em condições externas. Desse total, mantiveram-se três unidades foram mantidas envoltas em um "mucelin", obtendo-se, desse modo, a temperatura do bulbo seco e a do úmido. Instalaramse os termopares em microabrigos construídos em acrílico, que garantiu a boa exposição dos sensores e, ao mesmo tempo, evitou a radiação solar direta e parte da difusa (CunHA et al., 2001).

Os microabrigos foram mantidos eqüidistantes uns dos outros em $0,5 \mathrm{~m}$ e, por igual distância, acima do dossel da cultura; assim, à medida que a cultura se desenvolvia, os microabrigos eram elevados até atingir, no final do ciclo, as alturas de 2,5; 3,0 e 3,5 m, para os níveis 1,2 e 3 respectivamente. O saldo de 
Quadro 1. Relação de pragas e doenças diagnosticadas ao longo dos ciclos, produto químico e doses utilizadas do produto comercial $^{(1)}$

\begin{tabular}{lcc}
\hline Praga/doença & Produto comercial & Doses \\
\hline Vaquinha (Diabrotica speciosa) & Estron & $2 \mathrm{~mL} \cdot \mathrm{L}^{-1}$ \\
Pulgão (Macrosiphum euphorbiae) & Decis & $7 \mathrm{~mL}_{10 \mathrm{~L}}^{-1}$ \\
Oídio (Sphaerothea fuliginea) & Rubigan $120 \mathrm{CE}$ & $20 \mathrm{~mL} \cdot 100 \mathrm{~L}^{-1}$ \\
Míldio (Pseudoperonospora cubensis) & Ridomil & $300 \mathrm{~g} \cdot 100 \mathrm{~L}^{-1}$ \\
\hline
\end{tabular}

$\left({ }^{1}\right)$ A citação de marcas comerciais não indica recomendação dos autores.

radiação (SR) foi monitorado por sensores da Radiation and Energy Balance Systems (REBS) instalados a 2,2 $\mathrm{m}$ de altura e com as seguintes constantes de calibração: KSRin $=9,14 \mathrm{~W} \cdot \mathrm{m}^{-2} \cdot \mathrm{mV}^{-1}$ e KSRext $=$ $13,4 \mathrm{~W} \cdot \mathrm{m}^{-2} \cdot \mathrm{mV}^{-1}$. Dois fluxímetros foram instalados a $0,02 \mathrm{~m}$ de profundidade para monitorar o fluxo de calor no solo $(\mathrm{G})$ e dispostos na parcela central da área experimental entre duas linhas de plantio, um em ambiente protegido, outro em condições externas. As constantes de calibração utilizadas foram KGint = $35,8 \mathrm{~W} \cdot \mathrm{m}^{-2} \cdot \mathrm{mV}^{-1}$ e KGext $=36,2 \mathrm{~W} \cdot \mathrm{m}^{-2} \cdot \mathrm{mV}^{-1}$.

Esse conjunto de sensores, totalizando 20 canais foi conectado a um sistema de aquisição de dados (Datalogger) modelo 21X da Campbell Sci., por intermédio de um multiplexador para até 32 canais. Os dados, coletados em uma freqüência de $15 \mathrm{~s}$, com médias armazenadas a cada cinco minutos, foram transferidos para um microcomputador por meio de módulo de memória.

\subsection{Balanço de energia}

Calculou-se o balanço de energia pelo método da razão de Bowen. Considerou-se apenas o balanço vertical, pois os termos armazenamento de calor latente e sensível dentro da cultura são desprezíveis e a fração de energia utilizada em sínteses biológicas quase nunca ultrapassa $2 \%$ do saldo de radiação. A equação geral do balanço de energia pode ser descrita da seguinte forma:

$$
\mathrm{SR}+\mathrm{H}+\mathrm{LE}+\mathrm{G} \cong 0
$$

em que: SR é o saldo de radiação sobre a superfície; $H$ é o fluxo convectivo de calor sensível; LE é o fluxo convectivo de calor latente (evapotranspiração), e G é o fluxo de calor no solo.

No cálculo do balanço de energia, os fluxos que chegavam ao sistema (cultura de pepineiro) foram considerados positivos, enquanto os fluxos que saíam do sistema foram considerados negativos. Assim, o topo da cultura e a superfície do solo foram considerados os limites superior e inferior do sistema. Portanto, acima da cultura, os fluxos ascendentes eram negativos e vice-versa e, no interior do solo, os fluxos ascendentes eram positivos e vice-versa. Estimaramse os valores He LE pela razão de Bowen, descrita por ViLla Nova (1973):

$$
\begin{aligned}
& \beta=\frac{1}{\left(\frac{S+\gamma}{\gamma}\right) \cdot\left(\frac{\Delta T_{u}}{\Delta T}-1\right)} \\
& \beta=\frac{H}{L E}
\end{aligned}
$$

em que: $\Delta \mathrm{Tu}$ e $\Delta \mathrm{T}$ representam os gradientes de temperatura de bulbo úmido e seco entre o nível superior e inferior.

Os valores de $\mathrm{S}$ e $\gamma$ foram obtidos pelos modelos propostos por MURRAY (1967) e BRUNT (1952) respectivamente, ambos citados por AlLEN et al. (1998):

$$
\begin{aligned}
& S=\frac{2504 \exp \left(\frac{17,27 T}{T+237,2}\right)}{(T+237,3)^{2}} \\
& \gamma=0,00163 \frac{P}{\lambda}
\end{aligned}
$$

em que: T é a temperatura média do bulbo seco $\left({ }^{\circ} \mathrm{C}\right)$ entre os dois níveis de medidas $\left(Z_{1}\right.$ e $\left.Z_{2}\right)$; P é a pressão atmosférica $(\mathrm{kPa})$ - adotado valor médio de $90,66 \mathrm{kPa}$ para a região; $\lambda$ é o calor latente de evaporação, obtido por $\lambda=2,501-\left(2,361 \cdot 10^{-3}\right) \mathrm{T}$ (HARRISON, 1963, citado por Allen et al., 1998).

Conhecida a razão de Bowen, obtiveram-se os valores de LE e H, por:

$$
\begin{aligned}
& \mathrm{LE}=-\frac{(\mathrm{SR}-\mathrm{G})}{(1+\beta)} \quad(\beta \neq-1) \\
& \mathrm{H}=\mathrm{SR}-\mathrm{LE}-\mathrm{G}
\end{aligned}
$$

Procedeu-se à validação de estimativas do componente do balanço de energia, uma vez que os valores de $\mathrm{H}$ e LE são estimativas a partir de outros elementos, entre eles o G e o SR. Um método simplificado é estabelecer as relações entre o somatório do fluxo de calor latente e sensível (H + LE) e a energia disponível representado pelo somatório do saldo de radiação e o fluxo de calor no solo $(S R+G)$. 


\section{RESULTADOS E DISCUSSÃO}

\subsection{Balanço de energia em escala diária}

A figura 1 mostra uma curva típica da partição do balanço de energia dentro (A) e fora (B) da casa de vegetação. Observa-se que a curva de LE apresenta-se inversa à curva de SR, ou seja, valores positivos de SR representam energia para o meio e, conseqüentemente, fluxos de calor latente de evapotranspiração, saída de energia do meio. Em meio externo, o fluxo de calor sensível representa entrada de energia contribuindo para valores de LE superiores a SR. O quadro 2 mostra a partição dos componentes do balanço de energia para a data de 21/12/98, nos dois ambientes.

Pelo quadro 2, nota-se que o meio externo apresentou maior advecção de calor sensível devido à maior velocidade do vento (vento interno praticamente zero e externo com média de 2,05 m.s ${ }^{-1}$ ), contribuindo para o aumento da energia disponível, com os valores de LE sendo $8,2 \%$ maior do que o saldo de radiação. Totalizando todos os fluxos de entrada e saída de energia dos meios, pode-se concluir que o balanço foi praticamente nulo nos dois ambientes.

A figura 2 mostra a variação da razão de Bowen calculada para os dois ambientes. Observa-se no meio interno (Figura 2A) maior número de valores entre o intervalo de $-0,2$ e $+0,2$ ao passo que em meio externo houve maior variação dos valores da razão de Bowen, justamente em função da maior velocidade de inversão dos gradientes de temperatura por causa do maior turbilhonamento da atmosfera, resultado de velocidades do vento superiores neste ambiente. Observa-se, ainda nesta figura, valores elevados da razão de Bowen nos horários próximos ao nascer e ao pôr-do-sol em ambos os ambientes.

\subsection{Balanço de energia em ciclo de outono-inverno}

O saldo de radiação totalizou 693,68 MJ.m². Percentualmente, o fluxo de calor no solo $(\mathrm{G})$ representou 0,32\% do SR. Esse baixo valor pode estar associado ao sombreamento do solo pela cultura ao longo de quase todo o ciclo e também à diminuição da radiação direta no interior da casa de vegetação (Figura 3 - A e B).
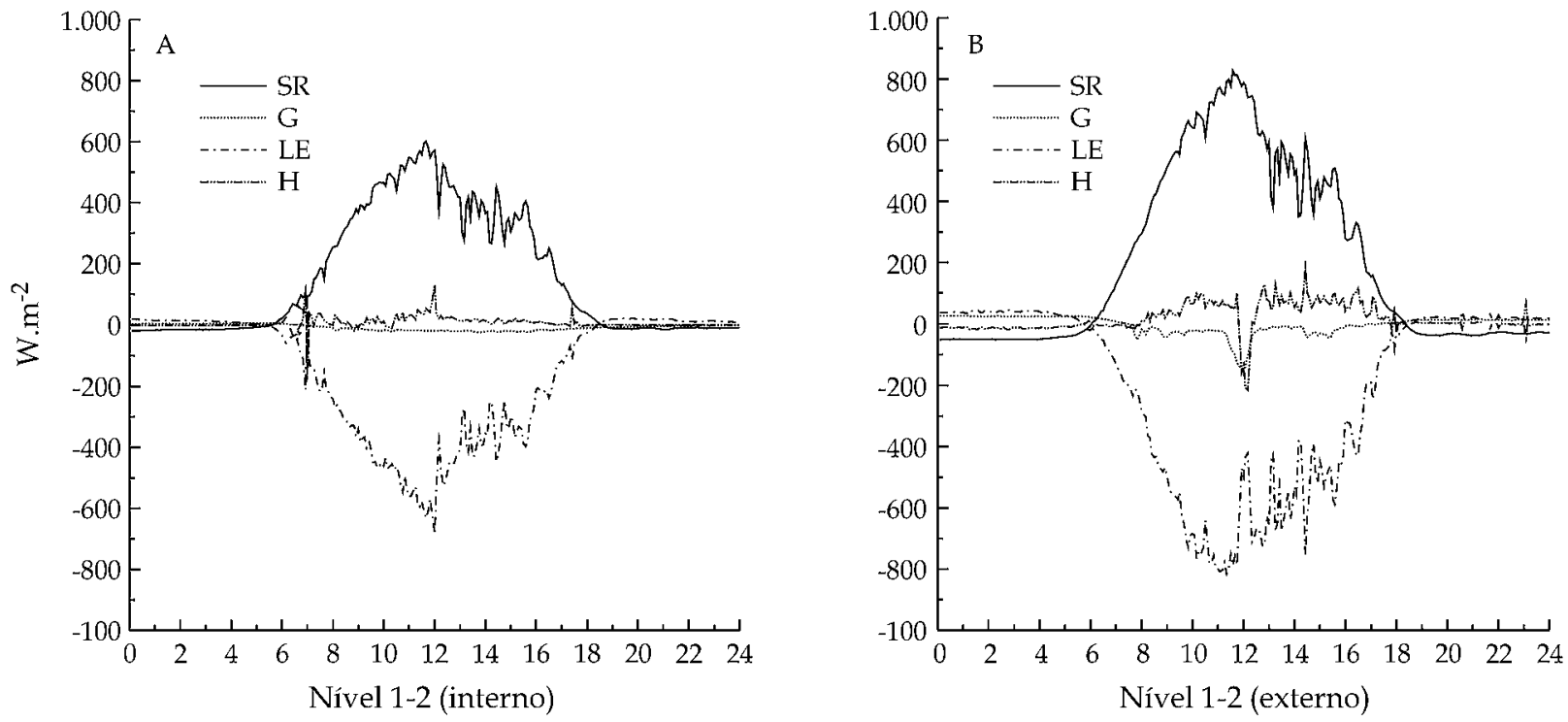

Figura 1. Curvas instantâneas de saldo de radiação (SR), fluxo de calor no solo (G), fluxo convectivo de calor latente (LE) e de calor sensível (H) para a data de 21/12/98 em condições interna (A) e externa (B), em Botucatu (SP).

Quadro 2. Relações entre saldo de radiação (SR), fluxo de calor no solo (G), fluxo de calor latente (LE) e sensível (H) para os níveis 1-2 em condição interna, em 21/12/98

\begin{tabular}{|c|c|c|c|c|c|c|c|c|}
\hline \multirow{2}{*}{ Variáveis } & \multicolumn{4}{|c|}{ Ambiente interno } & \multicolumn{4}{|c|}{ Ambiente externo } \\
\hline & SR & G & LE & $\mathrm{H}$ & SR & G & LE & $\mathrm{H}$ \\
\hline MJ.m ${ }^{-2} \cdot \mathrm{dia}^{-1}$ & $+13,36$ & $-0,66$ & $-13,22$ & $+0,53$ & $+17,02$ & $-0,169$ & $-18,42$ & $+1,53$ \\
\hline$\%$ de SR & $100,0 \%$ & $-4,94 \%$ & $-98,95 \%$ & $+3,97 \%$ & $100,0 \%$ & $-0,99 \%$ & $-108,2 \%$ & $+8,99 \%$ \\
\hline $\mathrm{G}+\mathrm{H}+\mathrm{LE}$ & \multicolumn{4}{|c|}{$99,92 \%$} & \multicolumn{4}{|c|}{$100,20 \%$} \\
\hline
\end{tabular}


Os fluxos de calor sensível $(\mathrm{H})$ quantificados entre os níveis 1-2 e 2-3 em ambiente interno representaram um acréscimo de $9,4 \%$ e $17,1 \%$, contribuindo para valores de fluxo de calor latente (LE) em 8,4\% e 16,4\% superiores ao SR. Esse acréscimo diferenciado de $\mathrm{H}$ entre os níveis 1-2 e 2-3 pode ser explicado pelo fato de os níveis superiores estarem sujeitos à maior advecção, intensificada pela maior ação do vento com a altura acima do solo. Na contabilização de todos os fluxos $(\mathrm{G}+\mathrm{H}+\mathrm{LE})$, respeitando as convenções de sinais apresentadas em Material e Métodos, encon-

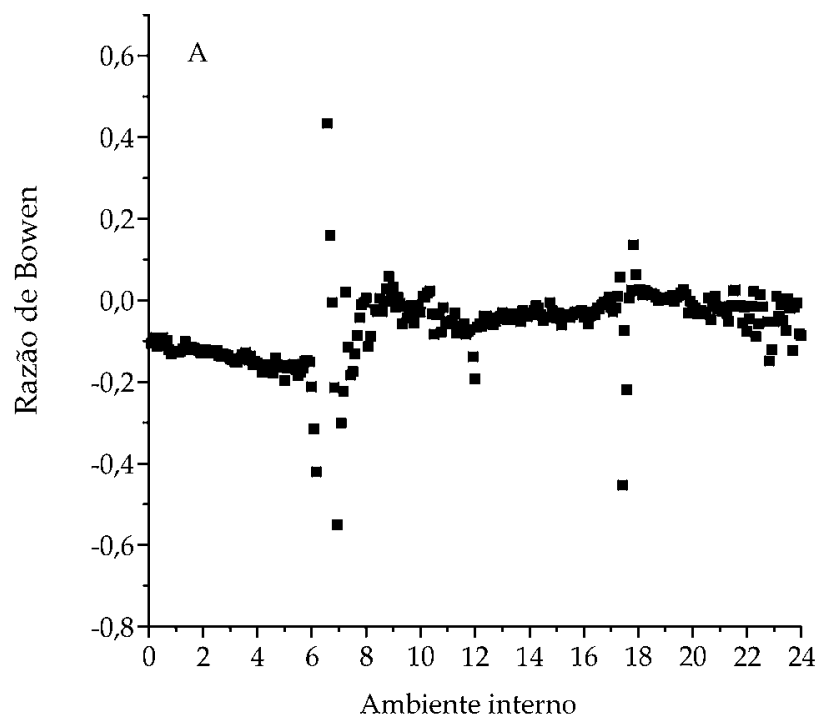

traram-se valores de $98,7 \%$ e $98,9 \%$ do saldo de radiação disponível (Figura 3 e Quadro 3).

Para a condição de ambiente externo, o saldo de radiação totalizou $808,04 \mathrm{MJ} \cdot \mathrm{m}^{-2}$ durante todo o ciclo $(100 \%)$. O fluxo de calor no solo representou, desse total, valores negativos que correspondem a 2,1\% $\left(-17,064 \mathrm{MJ} \cdot \mathrm{m}^{-2}\right)$. Os fluxos de calor sensível representaram 5,9\% (-47,46 MJ.m $\left.{ }^{-2}\right)$ e 3,6\% (-28,75 MJ.m $\left.{ }^{-2}\right)$ para os níveis 1-2 e 2-3 respectivamente. Os fluxos de calor latente representaram $86,1 \%$ e $91,1 \%$, para os níveis 1-2 e 2-3 respectivamente. A integração dos valores de $\mathrm{H}$, $\mathrm{LE}$ e $\mathrm{G}$, respeitando as convenções de

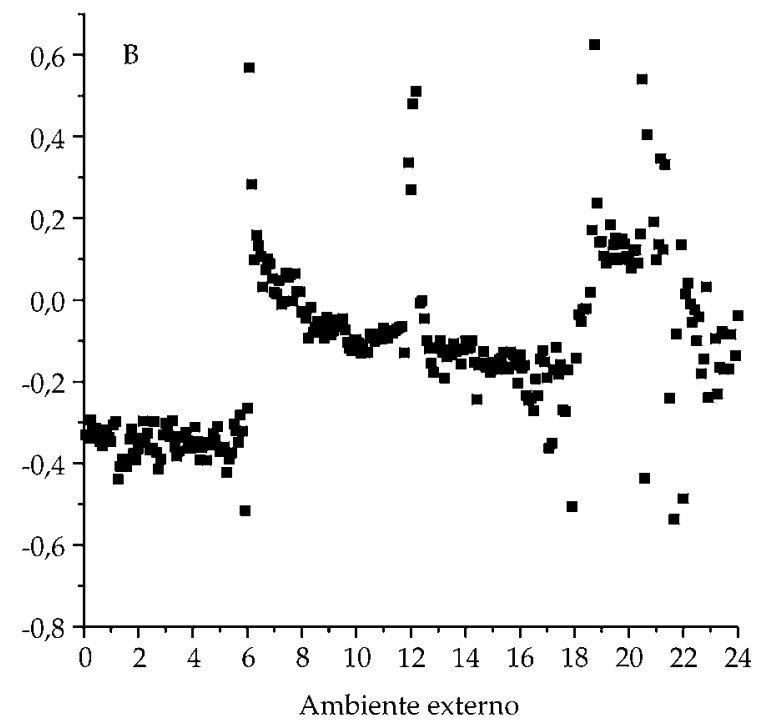

Figura 2. Variação da razão de Bowen (calor sensível/fluxo convectivo de calor latente) ao longo do dia 21/12/98 calculada para os níveis 1-2 em condição interna (A) e externa (B), em Botucatu (SP).

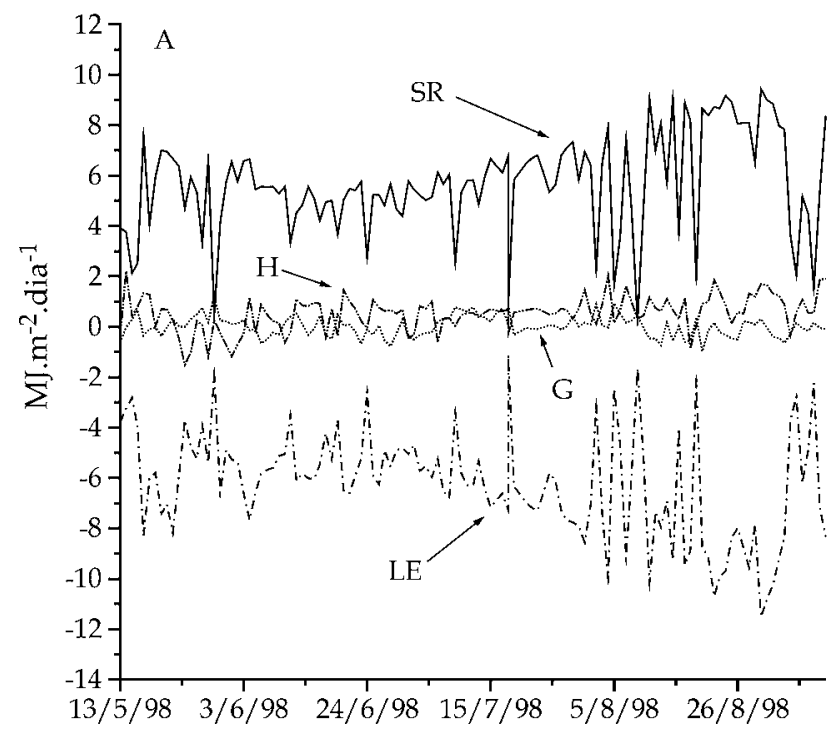

Nível 1-2 interno

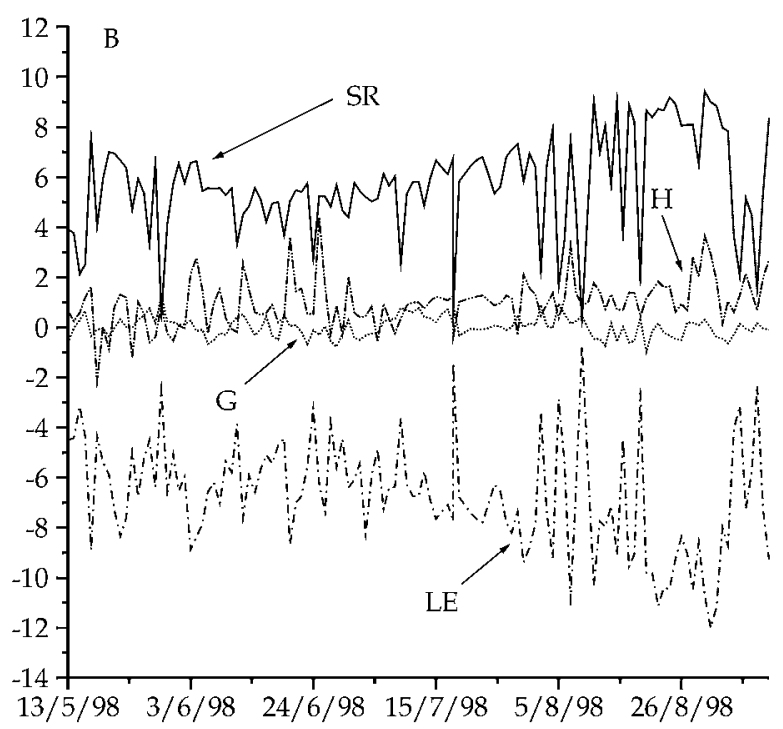

Nível 2-3 interno

Figura 3. Variação do saldo da radiação (SR), fluxo de calor no solo (G), fluxo de calor latente (LE) e sensível (H) entre os níveis 1-2 (A) e 2-3 (B), em condição interna, durante o ciclo de outono-inverno na cultura de pepineiro, em Botucatu (SP). 
entradas e saídas de energia do meio, representou 94,1\% (nível 1-2) e 96,7\% (nível 2-3) do SR, evidenciando que a parcela externa sofreu, durante o ciclo, perdas laterais de energia devido à advecção (Figura 4 e Quadro 4).

CunHa et al. (1996) encontraram, em cultura de alfafa, $86 \%$ para o fluxo de calor latente de evapotranspiração, $9 \%$ para o de calor sensível e $5 \%$ para o de calor no solo. Pedro Júnior e Villa Nova (1981), verificaram, em soja, valores de $72 \%$ para o fluxo de calor latente de evaporação, $13 \%$ para fluxo de calor sensível e $15 \%$ para fluxo de calor no solo, em relação ao saldo de radiação ou, como citam os autores, da energia líquida disponível no meio. AlfonsI et al.
(1986) observaram, em cultura de milho, a relação de $84 \%, 2 \%$ e $14 \%$ para LE, H e G respectivamente.

FONTANA et al. (1991) obtiveram, em cultura de soja, $95 \%$ e $78 \%$ do saldo de radiação utilizado nos processos de evaporação/transpiração e $2 \%$ e $7 \%$ do saldo de radiação utilizado como fluxo de calor no solo, em parcela irrigada e não irrigada respectivamente. Esses mesmos autores encontraram relação inversa entre fluxo de calor sensível e fluxo de calor latente de evaporação. VILLA Nova et al. (1975) não observaram concordância entre valores de LE e SR pelo fato de LE depender primariamente do balanço de energia ao nível da superfície, que é defasado de seu valor ao nível de $0,80 \mathrm{~m}$.

Quadro 3. Relações entre saldo de radiação (SR), fluxo de calor no solo (G), fluxo de calor latente (LE) e sensível (H) (MJ.m ${ }^{-2}$ para os níveis 1-2 e 2-3 em condição interna, ao longo do ciclo de outono-inverno da cultura de pepineiro, em Botucatu (SP)

\begin{tabular}{lccccccc}
\hline \multirow{2}{*}{ SR } & G & LE 1-2 & LE 2-3 & H 1-2 & H 2-3 & \multicolumn{2}{c}{ G + LE + H } \\
\cline { 7 - 8 } & & & & & & Níveis 1-2 & Níveis 2-3 \\
\hline$+693,68$ & $+2,505$ & $-752,00$ & $-807,18$ & $+64,94$ & $+118,91$ & 684,56 & 685,76 \\
$100,00 \%$ & $+0,32 \%$ & $-108,4 \%$ & $-116,4 \%$ & $+9,4 \%$ & $+17,1 \%$ & $98,68 \%$ & 98,86 \\
\hline
\end{tabular}

Quadro 4. Relações entre saldo de radiação (SR), fluxo de calor no solo (G), fluxo de calor latente (LE) e sensível (H) (MJ.m) para os níveis 1-2 e 2-3 em condição externa, na cultura de pepineiro, em Botucatu (SP)

\begin{tabular}{|c|c|c|c|c|c|c|c|}
\hline \multirow{2}{*}{ SR } & \multirow{2}{*}{ G } & \multirow{2}{*}{ LE 1-2 } & \multirow{2}{*}{ LE 2-3 } & \multirow{2}{*}{ H 1-2 } & \multirow{2}{*}{ H 2-3 } & \multicolumn{2}{|c|}{$\mathrm{G}+\mathrm{LE}+\mathrm{H}$} \\
\hline & & & & & & Níveis 1-2 & Níveis 2-3 \\
\hline$+808,04$ & $-17,064$ & $-695,84$ & $-736,27$ & $-47,46$ & $-28,75$ & $-760,36$ & $-781,08$ \\
\hline$+100,0 \%$ & $-2,11 \%$ & $-86,11 \%$ & $-91,12 \%$ & $-5,87 \%$ & $-3,56 \%$ & $94,10 \%$ & $96,66 \%$ \\
\hline
\end{tabular}

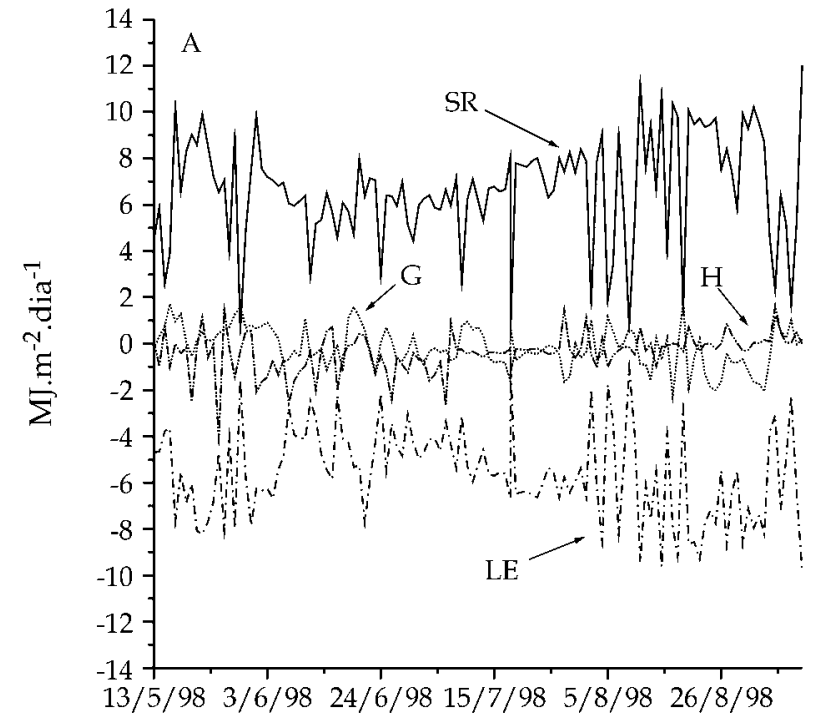

Nivel 1-2 externo

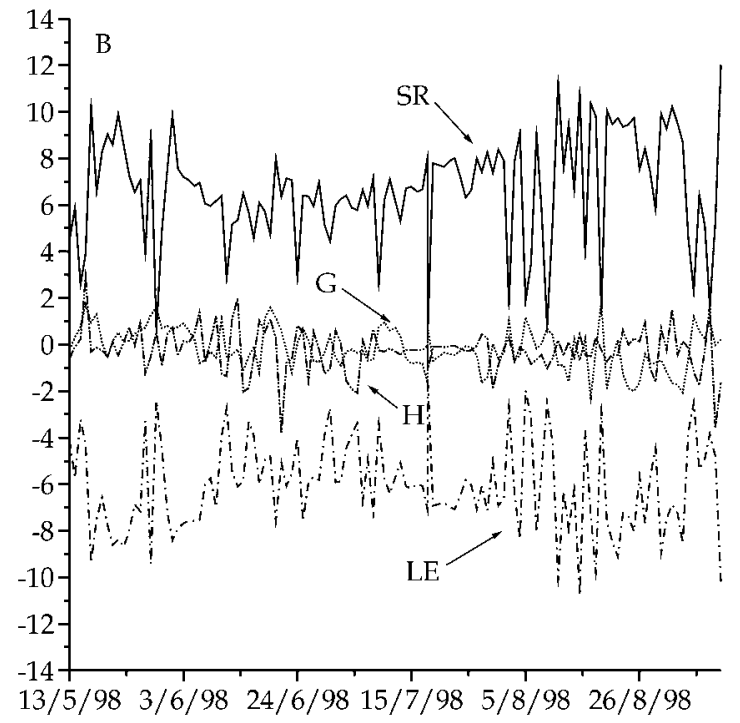

Nível 2-3 externo

Figura 4. Variação do saldo da radiação (SR), fluxo de calor no solo (G), fluxo de calor latente (LE) e sensível (H) entre os níveis 1-2 (A) e 2-3 (B), em condição externa, durante o ciclo de outono-inverno na cultura de pepineiro, em Botucatu (SP). 


\subsection{Balanço de energia em ciclo de primavera-verão}

$\mathrm{O}$ fluxo de calor no solo representou, em ambiente interno, 7,0\% do total de energia disponível (SR). Valores integrados de LE representaram $-101,1 \%$, ou seja, os fluxos de calor latente de evapotranspiração superaram a energia disponível o que pode ser explicado por valores positivos de $\mathrm{H}(+5,49 \%)$ que representam entrada de energia para o meio através de advecção ou armazenamento de calor dentro da casa de vegetação. Considerando todos os fluxos totalizados ao longo do ciclo e seus respectivos sinais, estes representaram para os níveis 1-2,102,6\% do saldo de radiação disponível (Figura 5 - A e B e Quadro 5).

A análise dos dados obtidos pelos cálculos dos fluxos entre os níveis 2-3 mostra valores de LE totalizando $-69,5 \%$ do saldo de radiação e $\mathrm{H}$ representando $-15,6 \%$. Totalizando-se os fluxos de LE, He G, obtevese a marca de $92,1 \%$ do saldo de radiação.

A contabilização de todos os fluxos em meio externo consta do quadro 6. Pode-se observar que o $G$ representou $-0,94 \%$ da energia disponível; os fluxos de calor latente de evaporação representaram para os níveis 1-2 um percentual de $-115,6$, superando os valores de SR, resultado da contribuição dos valores de $\mathrm{H}$ que representaram $+15,0 \%$ de SR. Contabilizando-se $\mathrm{H}+\mathrm{LE}$ $+\mathrm{G}$, obtém-se o valor de $1.242,41 \mathrm{MJ} \cdot \mathrm{m}^{-2}$, representando 1,5\% superior a SR. Para os níveis 2-3 observam-se os valores de LE da ordem de $-109,5 \%$ de SR e $\mathrm{H}+17,2 \%$; no somatório de todos os fluxos encontramse $1.140,56$ MJ.m ${ }^{-2}$ ou $93,2 \%$ de SR (Figura 6).

\subsection{Validação do balanço de energia em ciclo de outono-inverno}

Deve-se proceder à validação de estimativas do componente do balanço de energia, uma vez que os valores dos fluxos de calor sensível e de calor latente advêm de outros elementos, entre eles o fluxo de calor no solo e o saldo de radiação. Um método simplificado é estabelecer as relações entre o somatório do fluxo de calor latente e sensível (H + LE) e a energia disponível representado pelo somatório do saldo de radiação e o fluxo de calor no solo (SR - G).

A figura 7 apresenta os valores da relação $H+L E$ e SR - G para o ciclo de outono-inverno sobre cultura de pepineiro entre os níveis 1-2 e 2-3 nas condições de ambiente interno e externo respectivamente.

Quadro 5. Relações entre saldo de radiação (SR), fluxo de calor no solo (G), fluxo de calor latente (LE) e sensível (H) (MJ.m²) para os níveis 1-2 e 2-3 no interior da casa de vegetação, na cultura de pepineiro, em Botucatu (SP)

\begin{tabular}{lccccccc}
\hline SR & G & LE 1-2 & LE 2-3 & H 1-2 & H 2-3 & \multicolumn{2}{c}{ G + LE + H } \\
\cline { 5 - 8 } & & & & & & Níveis 1-2 & Níveis 2-3 \\
\hline 982,39 & $-68,90$ & $-993,24$ & $-683,16$ & $+53,97$ & $-153,26$ & $1.008,17$ & 905,32 \\
$100,00 \%$ & $-7,01 \%$ & $-101,10$ & $-69,54$ & $+5,49$ & $-15,60$ & $102,62 \%$ & $92,15 \%$ \\
\hline
\end{tabular}
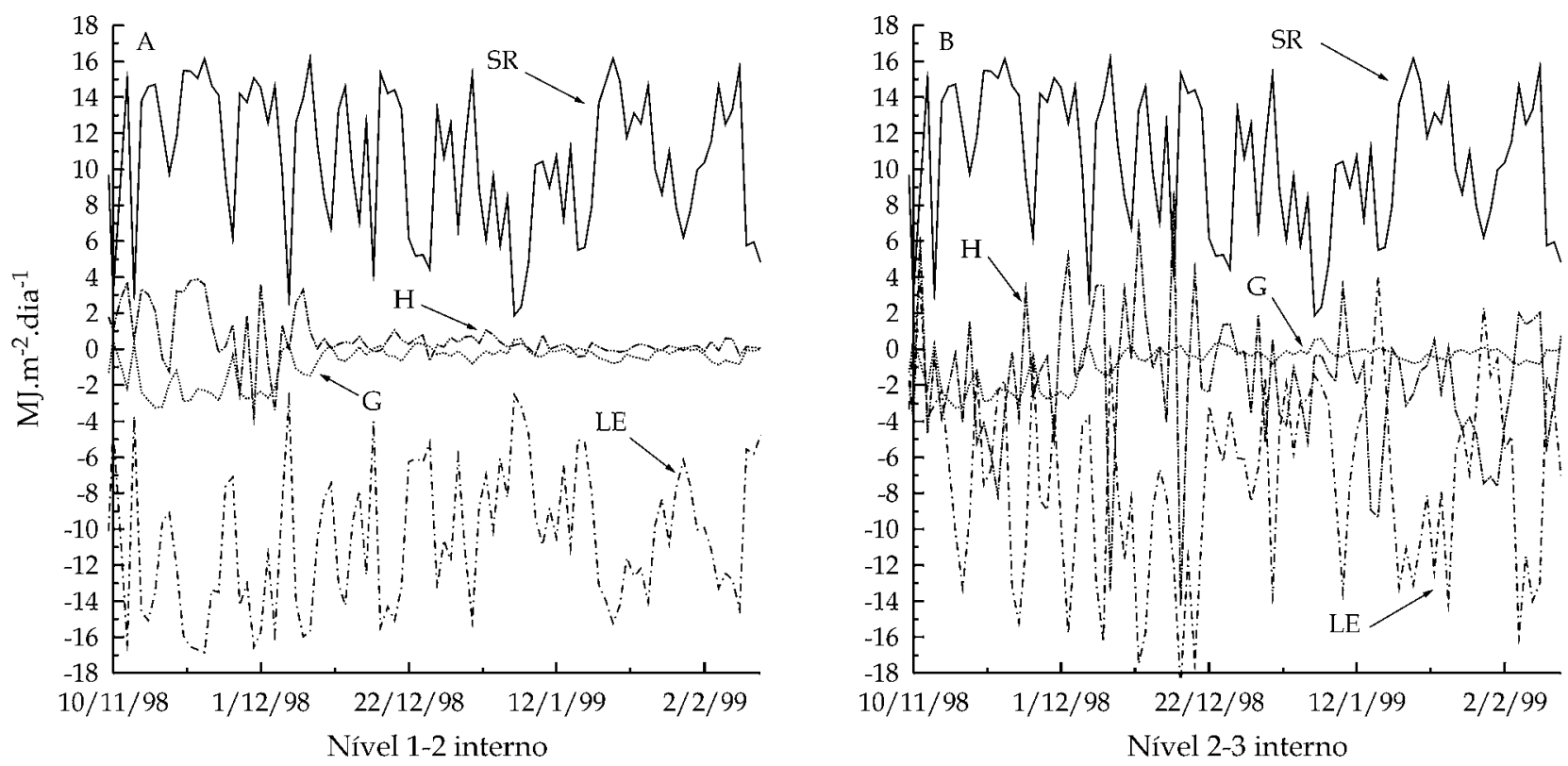

Figura 5. Variação do saldo da radiação (SR), fluxo de calor no solo (G), fluxo convectivo de calor latente (LE) e sensível (H) entre os níveis 1-2 (A) e 2-3 (B), em condição interna, durante o ciclo da cultura de pepineiro, em Botucatu (SP). 
Quadro 6. Relações entre saldo de radiação (SR), fluxo de calor no solo (G), fluxo de calor latente (LE) e sensível (H) (MJ.m ${ }^{-2}$ para os níveis 1-2 e 2-3 em condição externa, na cultura de pepineiro, em Botucatu (SP)

\begin{tabular}{|c|c|c|c|c|c|c|c|}
\hline \multirow{2}{*}{ SR } & \multirow{2}{*}{ G } & \multirow{2}{*}{ LE 1-2 } & \multirow{2}{*}{ LE 2-3 } & \multirow{2}{*}{ H 1-2 } & \multirow{2}{*}{ H 2-3 } & \multicolumn{2}{|c|}{$\mathrm{G}+\mathrm{LE}+\mathrm{H}$} \\
\hline & & & & & & Níveis 1-2 & Níveis 2-3 \\
\hline 1223,63 & $-11,45$ & $-1.413,97$ & $-1.340,15$ & $+183,01$ & $+2.11,04$ & $1.242,41$ & $1.140,56$ \\
\hline $100,00 \%$ & $-0,94 \%$ & $-115,56$ & $-109,5 \%$ & $+14,97 \%$ & $+17,25 \%$ & $101,53 \%$ & $93,21 \%$ \\
\hline
\end{tabular}
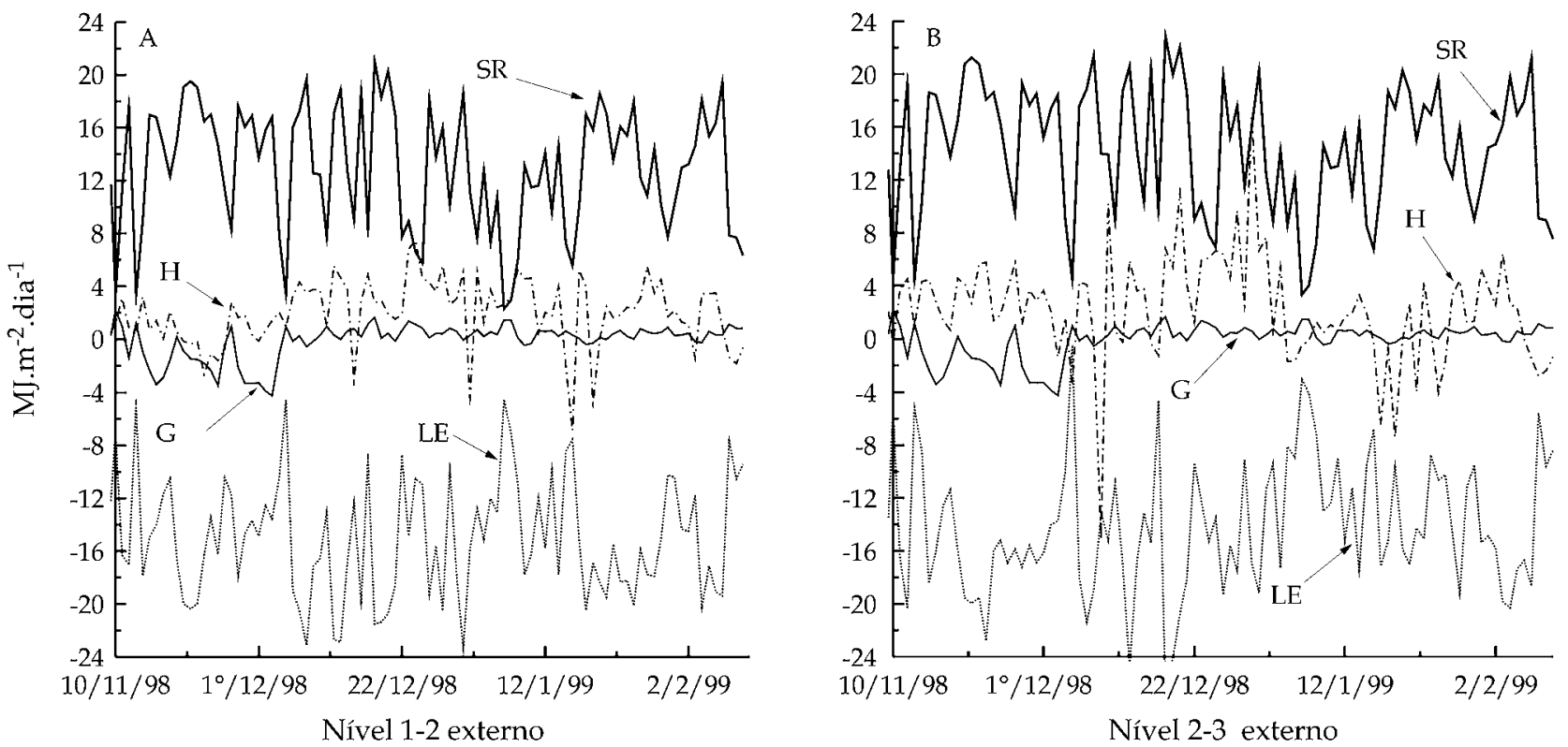

Figura 6. Variação do saldo da radiação (SR), fluxo de calor no solo (G), fluxo convectivo de calor latente (LE) e sensível (H) entre os níveis 1-2 (A) e 2-3 (B), em condição externa, durante o ciclo de primavera-verão na cultura de pepineiro, em Botucatu (SP).
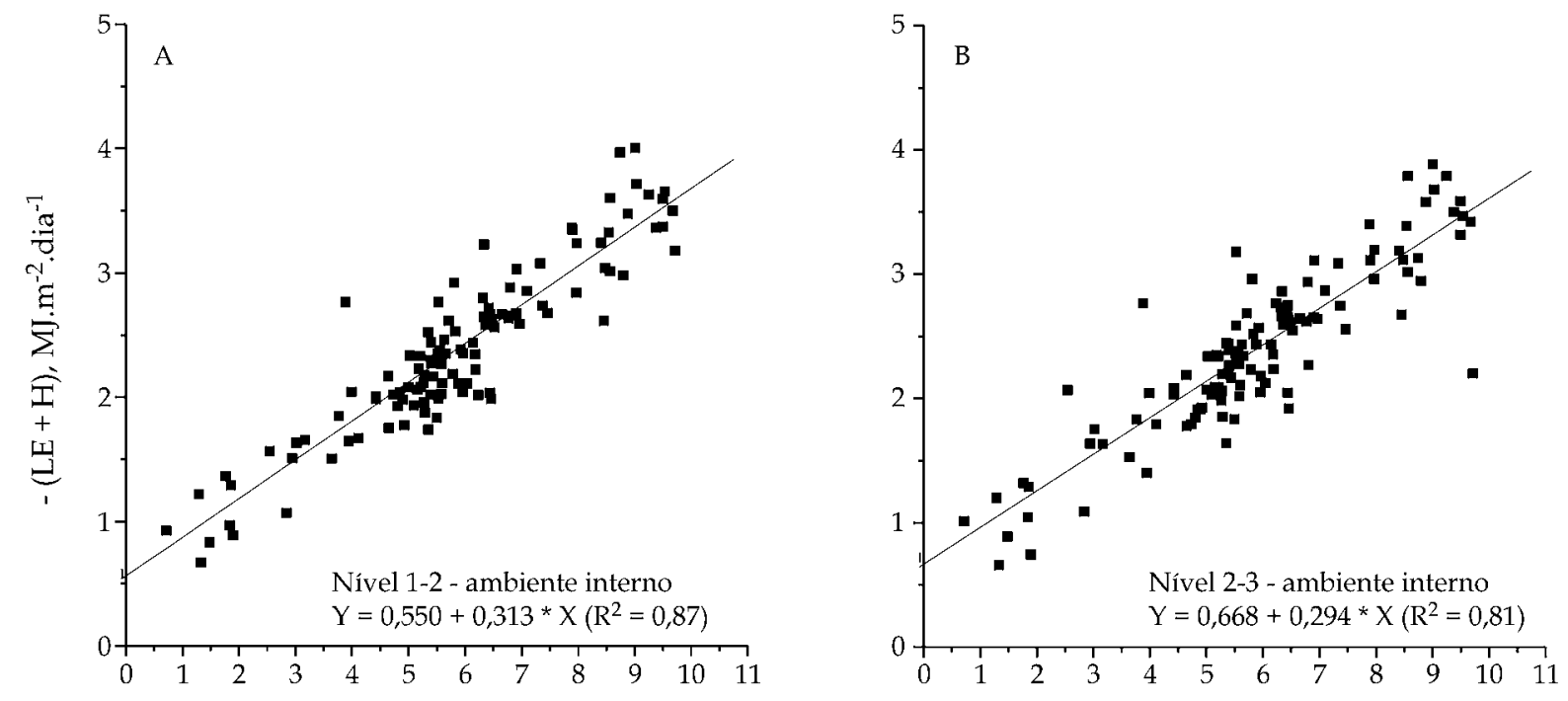

SR - G, MJ.m². $\mathrm{dia}^{-1}$

Figuras 7 A-B. Componentes do balanço de energia para o ciclo de outono-inverno em condições de ambiente interno sobre a cultura de pepineiro, nos níveis 1-2 e 2-3, A e B respectivamente, em Botucatu (SP). 

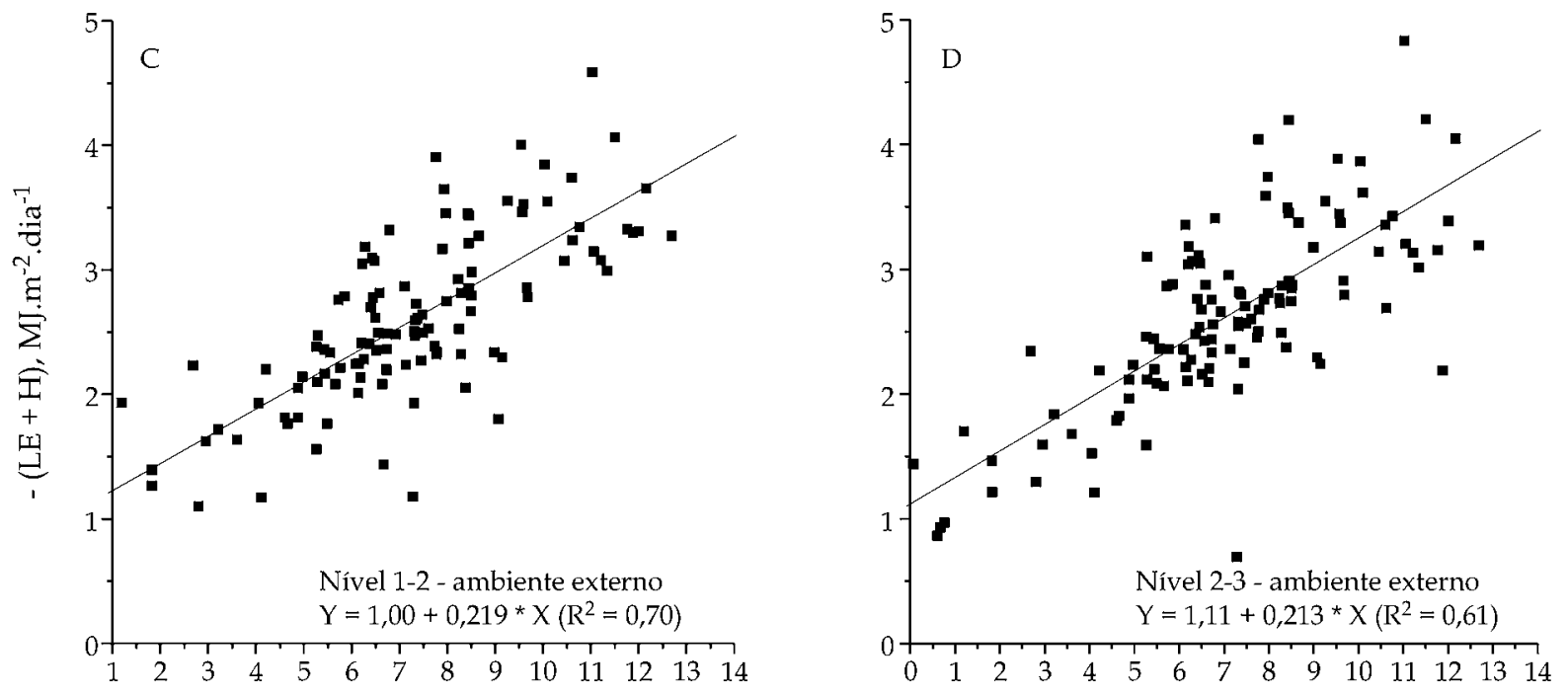

$$
\text { SR - G, MJ.m }{ }^{-2} \cdot \text { dia }^{-1}
$$

Figuras 7 C-D. Componentes do balanço de energia para o ciclo de outono-inverno em condições de ambiente externo sobre a cultura de pepineiro, nos níveis 1-2 e 2-3, C e D respectivamente, em Botucatu (SP).

Observam-se, no interior da casa de vegetação, valores do coeficiente de determinação mais elevados para ambos os níveis sobre a cultura: 0,87 e 0,81 contra 0,70 e 0,61, no ambiente externo, para os níveis 1-2 e 2-3 respectivamente. De modo geral, à medida que os níveis se elevam acima do dossel da cultura, os valores de $r^{2}$ diminuem, evidenciando o maior efeito do turbilhonamento da atmosfera e a inversão dos gradientes de temperatura e umidade nesses níveis. Silva et al. (1999), trabalhando com valores instantâneos $\left(\mathrm{W} \cdot \mathrm{m}^{-2}\right)$ obtidos sobre gramado, encontraram, para a relação $S R$ - G vs. $\mathrm{LE}+\mathrm{H}$, coeficientes de determinação da ordem de 0,89

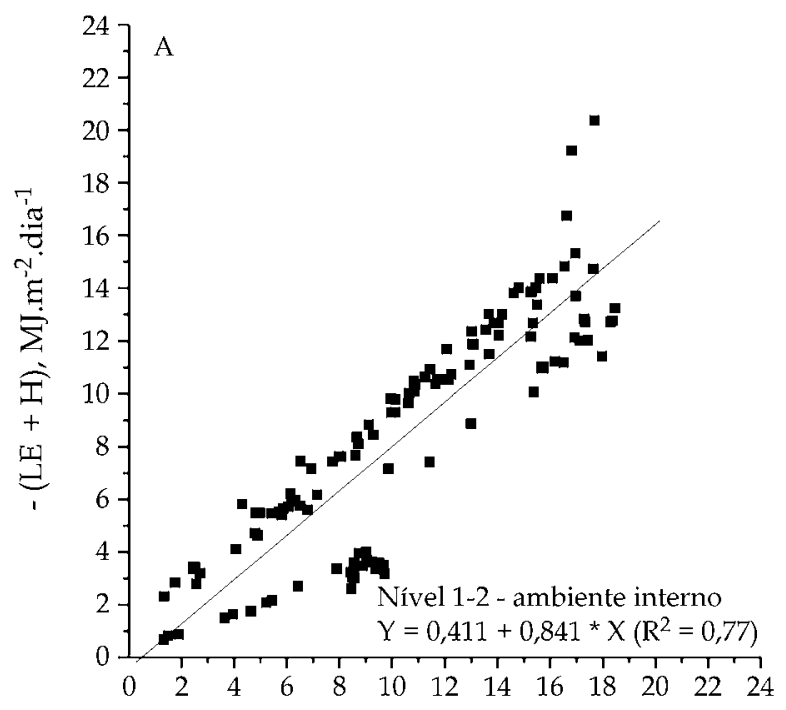

e 0,92 para dois dias de medida. PRUEGer et al. (1998) em análises semelhantes encontraram para condições de baixa velocidade do vento razão ( $\mathrm{LE}+\mathrm{H} / \mathrm{SR}$ - G) de 0,85 . Segundo esses mesmos autores, esse valor é aceitável para estudos de balanço de energia sobre culturas.

\subsection{Validação do balanço de energia em ciclo de primavera-verão}

A figura 8 apresenta os valores da relação $\mathrm{H}+\mathrm{LE}$ e SR - G para o ciclo de primavera-verão sobre cultura de pepineiro entre os níveis 1-2 e 2-3 nas condições de ambiente interno e externo respectivamente.

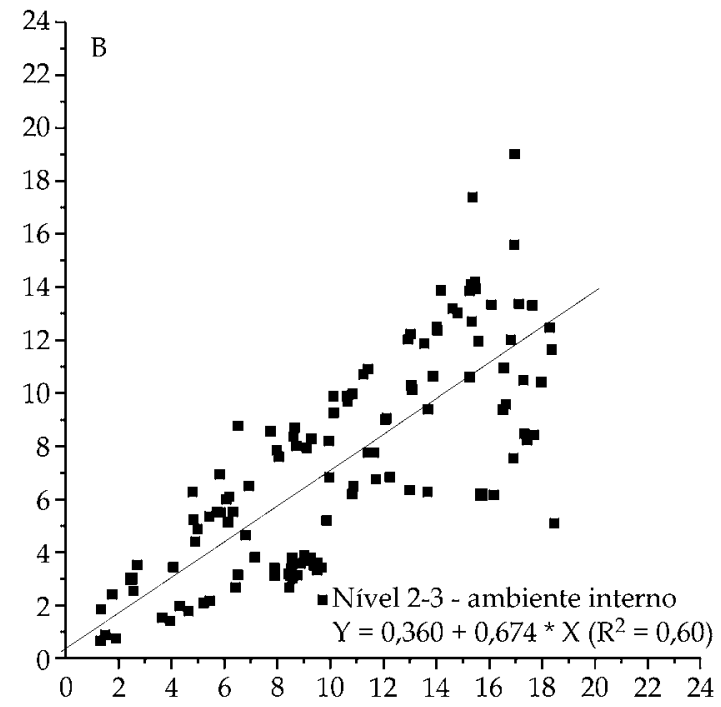

$$
\text { SR - G, MJ.m-2 } \text { dia }^{-1}
$$

Figuras 8 A-B. Componentes do balanço de energia para o ciclo de primavera-verão em condições de ambiente interno (A e B) sobre a cultura de pepineiro, nos níveis 1-2 e 2-3, em Botucatu, SP. 


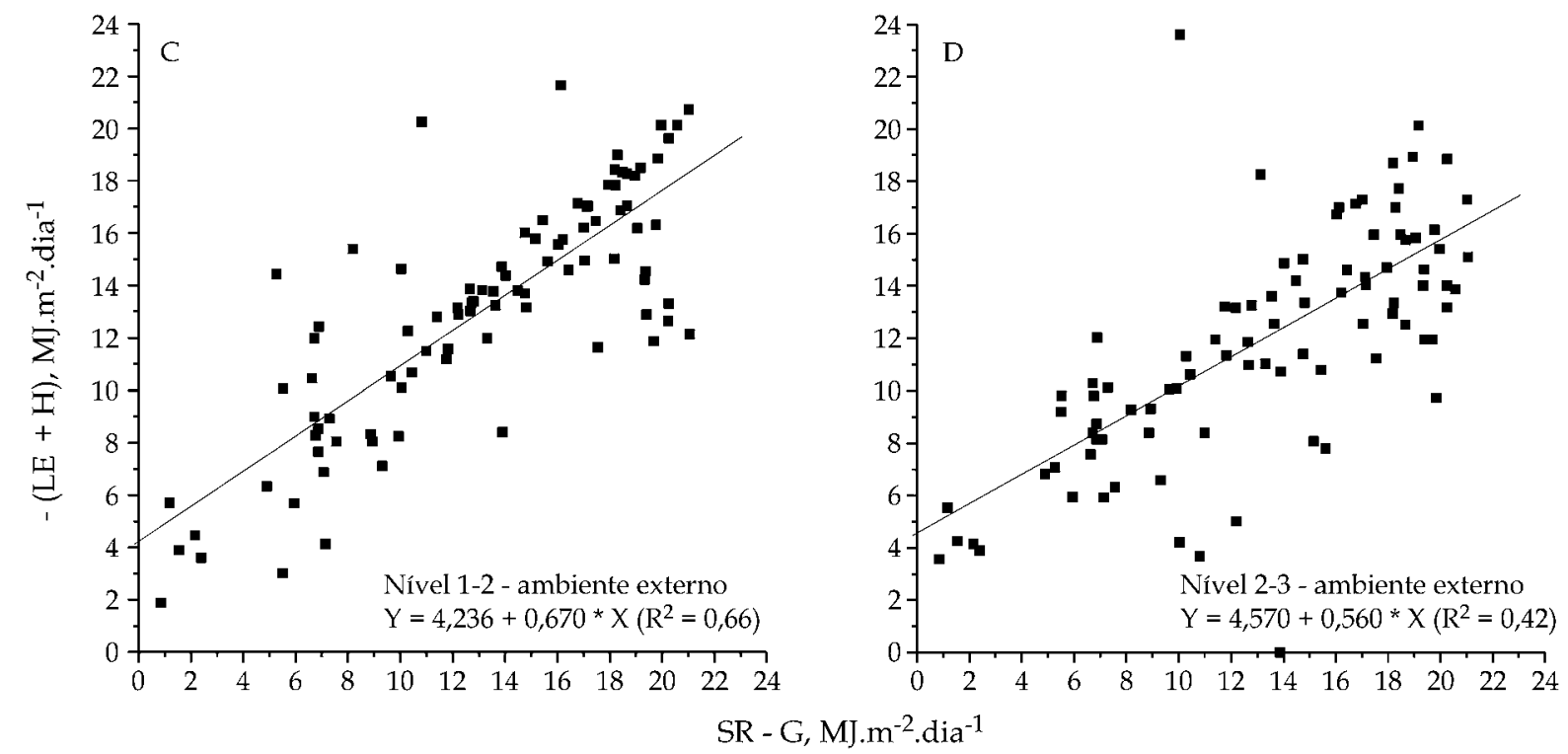

Figuras 8 C-D. Componentes do balanço de energia para o ciclo de primavera-verão em condições de ambiente externo (C e D) sobre a cultura de pepineiro, nos níveis 1-2 e 2-3, em Botucatu, SP.

Os coeficientes de determinação da relação SR - G vs. $\mathrm{LE}+\mathrm{H}$ para o ciclo de primavera-verão foram inferiores aos do ciclo de outono-inverno em ambos os ambientes e em níveis acima do dossel da cultura. Para o ambiente interno, encontram-se $\mathrm{r}^{2}$ da ordem de 0,77 e 0,60 para os níveis 1-2 e 2-3 respectivamente. No ambiente externo, para os níveis $1-2$, o ${ }^{2}$ foi 0,66 e, para o nível 2-3, 0,42. Semelhante ao ciclo de outono-inverno, os coeficientes de determinação mais baixos ocorreram justamente nos níveis mais elevados, ou seja, nos localizados acima do dossel da cultura. Isso pode estar associado, além das razões apresentadas no item anterior, à limitação do método do balanço de energia, que preconiza que as medidas sejam efetuadas a uma baixa altura e dentro de áreatampão suficientemente extensa, onde as divergências horizontais de calor latente e sensível sejam desprezíveis, ou seja, considerando apenas o balanço vertical, o que pode não ter ocorrido em função da área-tampão não ter sido suficientemente extensa para tornar desprezível a advecção de calor sensível de áreas vizinhas.

\section{CONCLUSÕES}

1. A maior parte da energia disponível foi utilizada no fluxo de calor latente de evaporação.

2. Observou-se contribuição do fluxo de calor sensível nos valores de energia disponível, contribuindo para o aumento dos valores de fluxo de calor latente.

3. O método do balanço de energia apresentou valores mais consistentes quando obtidos em condições internas e em ciclo de outono-inverno.

\section{REFERÊNCIAS BIBLIOGRÁFICAS}

ALLEN, R.G.; PEREIRA, L.S.; RAES, D.; SMITH, M. Crop evapotranspiration: Guidelines for computing crop water requirements. Rome: 1998. (FAO Irrigation and Drainage, 56). (http://www.fao.org/docrep/X0490E/ X0490E00.htm)

ALFONSI, R.R.; SANTOS FILHO, B.G. dos; PEDRO JUNIOR, M.J.; BRUNINI, O.; CAMARGO, M.B.P. de. Balanço de energia em milho. Pesquisa Agropecuária Brasileira, Brasília, v.21, n.12, p.1233-1235, 1986.

AZEVEDO, P.V. de.; LEITÃO, M. de M.V.B.R.; COSTA, J. de P.R. da. Balanço de energia numa cultura de soja irrigada nas condições semi-áridas do Nordeste. IN: CONGRESSO BRASILEIRO DE AGROMETEOROLOGIA, 6., 1989. Maceió. Anais... Maceió: Sociedade Brasileira de Agrometeorologia, 1989. p.427-435.

BERGAMASCHI, H.; OMETTO, J.C.; VIEIRA, H.J.; ANGELOCCI, L.R.; LIBARDI, P.L. Deficiência hídrica em feijoeiro. II. Balanço de energia. Pesquisa Agropecuária Brasileira, Brasília, v.23, n.7, p.745-757, 1988.

CUNHA, G.R. da; BERGAMASCHI, H.; BERLATO, M.A.; MATZENAVER, R. Balanço de energia em cultura de milho. Revista Brasileira de Agrometeorologia, Santa Maria, v.4, n.1, p.1-14, 1996.

CUNHA, A.R.; ESCOBEDO, J.F.; GALVANI, E. Quantificação da temperatura e umidade relativa do ar em ambiente protegido com psicicrômetro de termopar. In: CONGRESSO INTERNACIONAL DE INGENIERIA AGRÍCOLA, 4., 2001, Chilán, Chile. Memórias... Chilán, Chile: Faculdad de Ingenieria Agrícola, Universidad de Concepcion, 2001, p.127-130. 
FONTANA, D.C.; BERLATO, M.A.; BERGAMASCHI, H. Balanço de energia em soja irrigada e não irrigada. Pesquisa Agropecuária Brasileira, Brasília, v.26, n.3, p.403-410. 1991.

FRISINA, V.A. Otimização de um albedômetro e sua aplicação no balanço de radiação e energia em cultura de alface (Lactuca sativa L.) dentro e fora de estufa de polietileno. Botucatu, 1998. 89p. Dissertação (Mestrado em Energia na Agricultura) - Faculdade de Ciências Agronômicas, Universidade Estadual Paulista.

GALVANI, E.; DANTAS, R.T.; ESCOBEDO, J.F.; GAMERO GUANDIQUE, M.E. Balanço de energia em cultura de alface (Lactuca sativa L.) em condições de estufa com orientações leste-oeste e norte-sul. In: CONGRESSO BRASILEIRO DE AGROMETEOROLOGIA, 10., 1997. Piracicaba. Anais... Piracicaba: Sociedade Brasileira de Agrometeorologia, 1997. p.500-503.

JAEGER, L.; KESSLER, A. Twenty years of heat and water balance climatology at the Hartheim pine forest, Germany. Agricultural and Forest Meteorology, Amsterdam, v.84, p.25-36, 1997.

NISHIMURA, T.; ALMEIDA, A.; ANDRÉ, R.G.B.; VOLPE, C.; LIBERA, C.L.F.D., MALHEIROS, E.B. Balanço de energia numa cultura de milho (Zea mays L.). In: CONGRESSO BRASILEIRO DE AGROMETEOROLOGIA, 4., 1985. Anais... Londrina: Sociedade Brasileira de Agrometeorologia, 1985. p.83-92.

OLIVER, H.R.; SENE, K.J. Energy and water balances of developing vines. Agricultural and Forest Meteorology, Amsterdam, v.62, p.167-185, 1992.
PEDROJÚNIOR, M.J.; VILLA NOVA, N.A Balanço de energia em soja (Glycine max L. Merr). Turrialba, San José, v.31, n.4, p.309-312, 1981.

PRATES, J.E.; COELHO, D.T.; STEINMETZ, S.; SEDYANMA, G.C.; VIANELLO, R.L. Relações entre os componentes do balanço de energia em diferentes estádios de desenvolvimento do arroz (Oryza sativa L.) de sequeiro. In: CONGRESSO BRASILEIRO DE AGROMETEOROLOGIA, 1., Belém, 1987. Anais... Belém: Sociedade Brasileira de Agrometeorologia, 1987. p.333-336.

PRUEGER, J.H.; SAUER, T.J.; HATFIELD, J.L. Turbulence flux of sensible and latent heat near shelterbelts during low wind conditions. Transactions of the ASAE, Sant Joseph, v.41, n.6, p.1643-1650, 1998.

SILVA, F.C. da.; FURLAN, R.A.; FOLEGATTI, M.V. Estimativas de densidade de fluxo de calor sensível e latente através do método da razão de Bowen. In: CONGRESSO BRASILEIRO DE AGROMETEOROLOGIA, 11., 1999, Florianópolis. CD-ROM, Florianópolis: Sociedade Brasileira de Agrometeorologia, 1999.

VILLA NOVA, N.A. Estudos sobre balanço de energia em cultura de arroz. Piracicaba, 1973. 89p. Tese (LivreDocência) - Escola Superior de Agricultura "Luiz de Queiroz", Universidade de São Paulo.

VILLA NOVA, N.A.; PEREIRA, A.R.; PEDRO JÚNIOR, M.J. Balanço de energia em uma cultura de arroz em condições de sequeiro. Bragantia, Campinas, v.34, p.171176, 1975.

YANG, X. Greenhouse micrometeorology and estimation of heat and water vapour fluxes. Journal Agricultural Engineering Research, London, v.61, p.227-238, 995. 